\title{
OBTAINING AND TESTING COARSE GRAIN SIZE DISTRIBUTIONS FROM PHOTOGRAPHIC GRID COUNTS
}

\author{
Karalis S. ${ }^{1}$, Aytousmis A. ${ }^{1}$, Iordanou A. ${ }^{1}$, Karakostas G. ${ }^{1}$, Charatsis K. ${ }^{1}$ and \\ Karymbalis E. ${ }^{2}$
}

${ }^{1}$ Technological Educational Institute of Athens, School of Technological Applications, Department of Civil, Survey and Geoinformatics Engineering, Ag. Spyridonos, Egaleo, Greece, 12243, skaralis@teiath.gr

${ }^{2}$ Harokopio University, Department of Geography, 70 El. Venizelou Av., Kallithea, Greece, 17671, karymbalis@hua.gr

\begin{abstract}
The grain size distribution (GSD) of surface bed material in alluvial rivers is of interest in many geological, ecological and engineering applications. In this work, which is a part of our broader Ph.D research in Vouraikos river on sediment transport, we are testing the possibility of obtaining such a distribution from photographs taken at the field (grid sampling), compared with the standard method which is the "pebble count". We have also examined and quantified the errors resulting from radial distortion of the photographs. The motive of the work was to explore the opportunity of substituting field work for laboratory work. Results show that for this method to give reliable results, a better knowledge of the site-specific conditions is needed, which, in turn, requires more field work.

Keywords: pebble count, bed material, photogrammetry, photography, sediment transport.

\section{Пєрíi $\eta \psi \eta$}

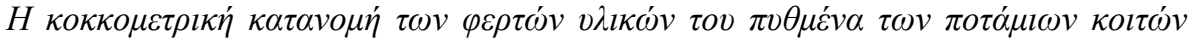

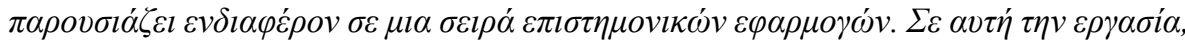

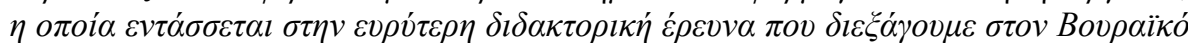

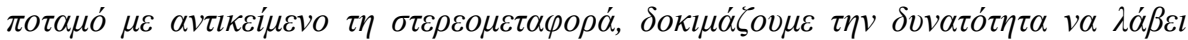

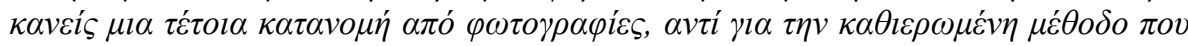

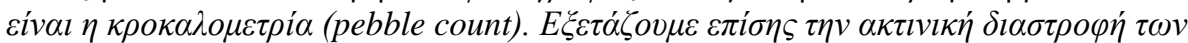

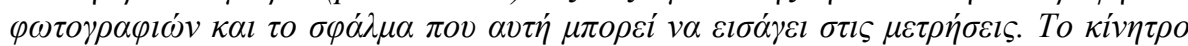

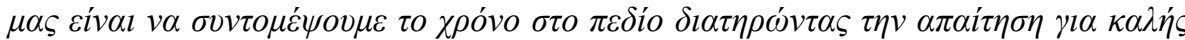

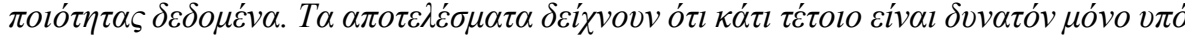

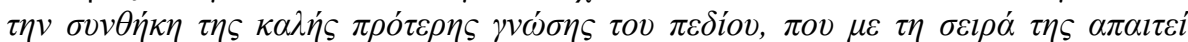

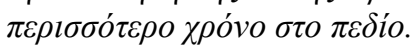

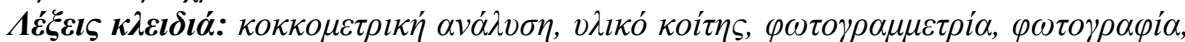
$\sigma \tau \varepsilon \rho \varepsilon о \mu \varepsilon \tau \alpha \varphi \rho \rho \dot{.}$
\end{abstract}

\section{Introduction}

Many applications from various scientific fields require the knowledge of the grain size distribution (GSD) of surface or subsurface bed material at certain sites along a river course. These scientific 
fields include geologists and geomorphologists that might be interested in sources and sinks of sediment within a catchment and the geomorphological evolution of the landscape, sedimentologists studying sedimentation environments, ecologists and environmental scientists that study the spawning conditions of certain wildlife species and engineers working in river restoration projects or need to estimate bedload transport rates.

The size of gravel particles can be measured manually or by sieving. The different equipment used in both approaches can affect the results. This makes it necessary to compare different methods of particle-size measurements. Manual measuring includes the use of rulers or calipers, the "pebble box", or the use of a template, an instrument also called gravelometer (see Fig.1). The use of gravelometer is preferred since it is much less prone to operator error. Sieving can be done in the field, but in most cases it is done in the laboratory. Sieving usually employs square-hole sieves (there are also round-hole sieves) that have gradations between 0.063 and $64 \mathrm{~mm}$. Sieve sizes (the side length of the mesh width) typically advance as logarithmic series based on 2 , i.e

$$
D_{s}=2^{x}
$$

where x usually assumes values in increment of 0.5 , so that $D_{s}$ advances in 0.5 units of $\varphi$ or $\psi$ scale. $\Phi$ is defined as $\Phi=-\log _{2}(D)$ (Wentworth, 1922) and $\Psi$ is defined as $\Psi=\log _{2}(D)$, where $D$ is the "diameter" of the pebble, that can be considered either as the nominal diameter, $D_{\mathrm{n}}=(\mathrm{a} \mathrm{b} \mathrm{c}){ }^{1 / 3}$ or just taken equal to the intermediate b-axis.
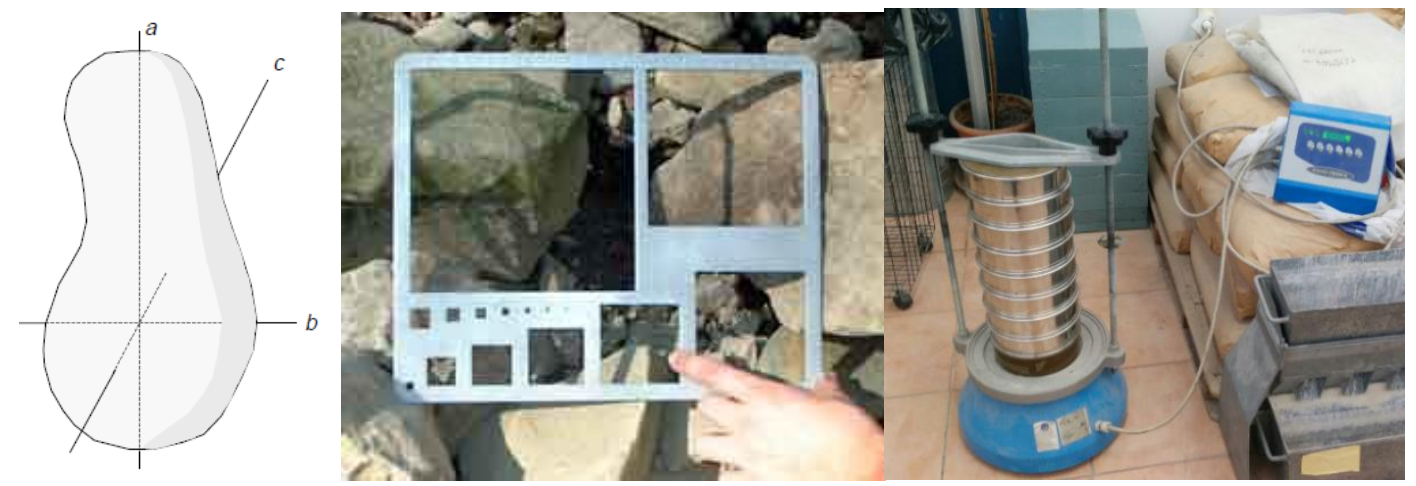

Figure 1 - Left, the three perpendicular axes of a particle, middle, the gravelometer and right, sieving in the laboratory with the aid of a shaker. Both the gravelometer and the sieves are supposed to measure the $b$-axis of the particle.

It should be pointed out here, that complete gravel surveys require the measurement of all three axes of a gravel (a,b,c, see Fig.1), and can be achieved either with the use of a ruler or a pebble box, while with the gravelometer, only the b-axis is measured. Relation between the b-axis and square-hole sieve sizes depend on the flatness of the particle (see Fig. 6). In addition, ruler measurements of baxes on photographs correspond to sieve results from round-hole sieves and need to be converted before they can be compared to standard sieve results from square-hole sieves (Bunte and Ampt, 2001).

\section{Study area}

The study area of our research is Vouraikos River in Northern Peloponnese. This river and its watershed has been the subject of an on-going Ph.D research (of the first author) that was initiated in 2012, and aims at quantifying and modelling sediment transport, with emphasis in bedload transport. 


\subsection{Geographical and geological setting}

The greater area of Northwestern Peloponnese consists, in the southern part, of geological formations of Mesozoic age (mainly limestones, but also cherts and flysch layers which belong to the geotectonic zones of Olonos-Pindos and Gavrovo-Tripolis, respectively). The northern part is dominated by Late Pliocene fluvial and lacustrine sands, silts and conglomerates, passing upwards to Quaternary marls and Gilbert-fan delta conglomerates (Bornovas and Rondoyanni, 1983).

The climate of the north Peloponnese is coastal Mediterranean (Köppen: Csb) with mean annual temperature $14.5^{\circ} \mathrm{C}$, mean temperature of the coldest month $10.6^{\circ} \mathrm{C}$ and mean temperature of the warmest month $26.4^{\circ} \mathrm{C}$ (Katsafados et al., 2012). Rainfall exhibits a gradient in the west-east direction ranging from more than $1500 \mathrm{~mm}$ of rain over the mountains of central Peloponnese to less than $450 \mathrm{~mm}$ in the east.

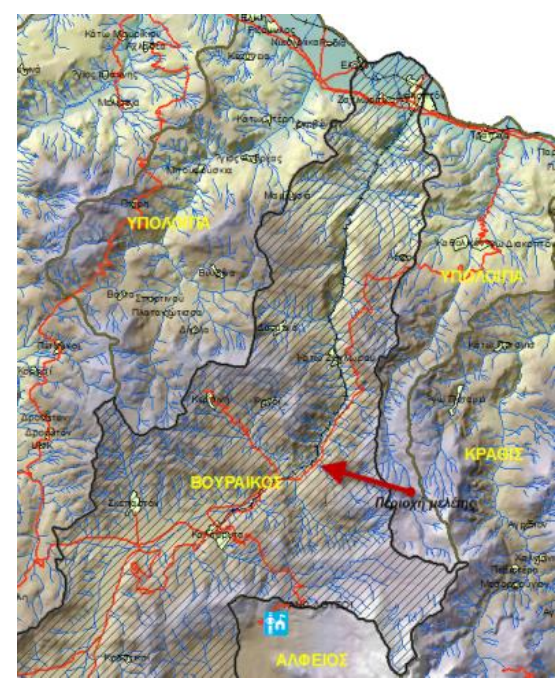

Figure 2 - Vouraikos basin (northern part) and study area.

\subsection{Description of the river reach}

The river of Vouraikos is made up, in general, by two distinct parts; It is characterised by a tranquil, slow flow in the valley of Kalavryta (small slope), while, after its exit from the valley (approximately downstream of the bridge of Kerpini), its slope increases and it becomes a roaring watercourse within a v-shaped, steep valley until almost the village of Zaxlorou. About $1 \mathrm{~km}$ upstream of the village of Zaxlorou, the v-shaped, steep valley becomes a gorge, for which this river is widely known.

In the study site (Pliatsikouras bridge) the stream can be classified broadly as plain bed type. Not far downstream, as its slope increases, it becomes a step - pool type. The average slope is $1.5 \%$. The principal sediment sources are fluvial, hillslope and debris flows while sediment storage is mainly overbank. These features can be seen in Fig. 2 and Fig. 3. 


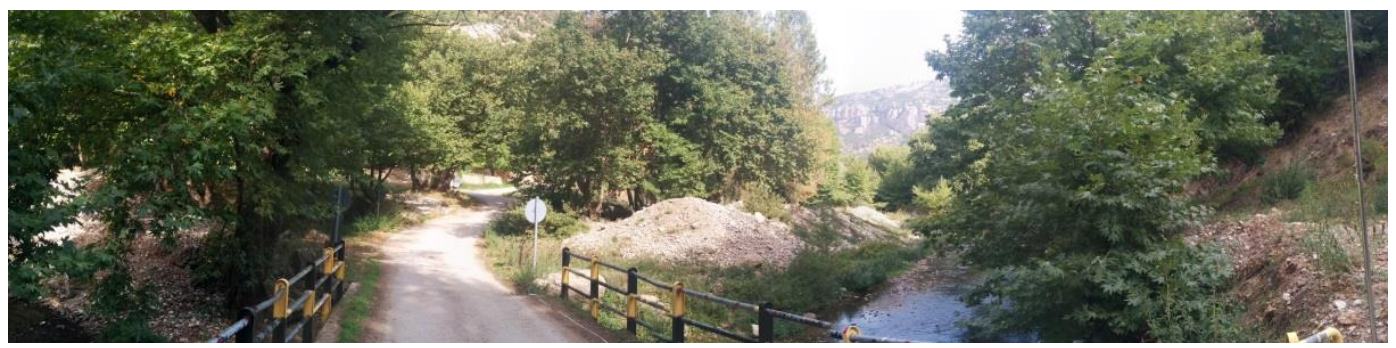

Figure 3 - Panoramic view of the stream, downstream of the Pliatsikouras bridge. The piles of gravels that can be seen in the left bank come from a tributary. Occasionally, this sediment is mechanically shovelled and piled overbank.

\section{Materials and Methods}

\subsection{Materials and instrumentation}

Bed surface sediment can be sampled by three methods:

- pebble counts (line counts): select and hand-pick a preset number of surface particles at even-spaced increments along transects that may be parallel and span a relatively large sampling area $\left(\sim 100 \mathrm{~m}^{2}\right)$,

- grid counts: select particles at a preset number of even-spaced grid points that span a relatively small sampling area $\left(\sim 1-10 \mathrm{~m}^{2}\right)$, hand-picking particles or measuring particle sizes on photographs, and

- areal samples: include all surface particles contained within a small preset area $\left(\sim 0.1-1 \mathrm{~m}^{2}\right)$ of the streambed, often using adhesives to ensure that small particles are included representatively in the sample.

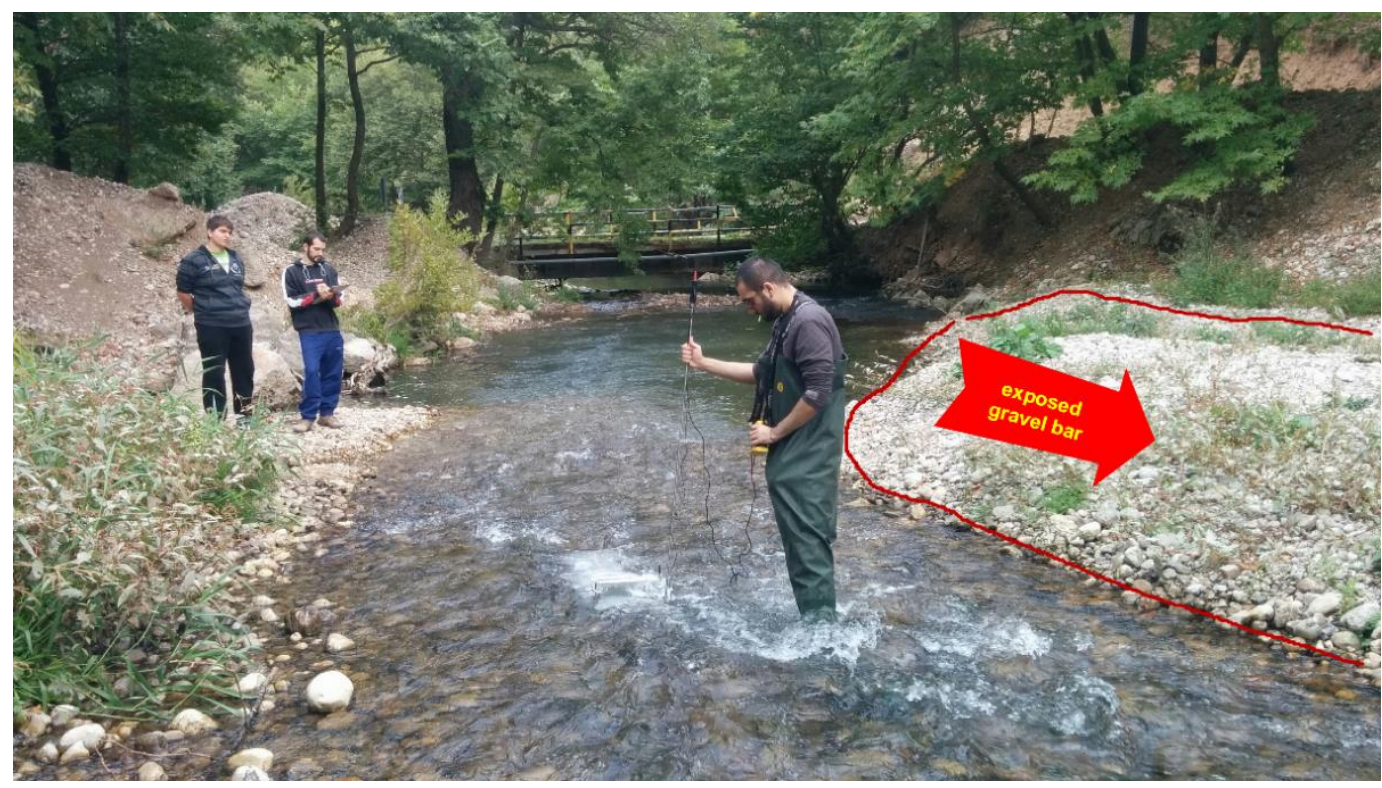

Figure 4 - The study site upstream of the Pliatsikouras bridge. Piles of sediment can be seen near the left bank. Our measurements were on the exposed gravel bar to the right of the picture. This material is bedload since it is carried from the high flows (floods). 
Pebble counts and grid counts are both suitable for gravel and cobbles (not for sand) and have been both employed in our research. In particular, we have carried out a pebble count of 150 particles using the gravelometer, and a photographic grid count on three photographs, both realised on the exposed gravel bar of the river (October 2015) upstream of the bridge of Pliatsikouras (see Fig.3). The pebble count was done over one line, materialised by the measuring tape laid on the ground, and picking one particle every $20 \mathrm{~cm}$, trying to avoid bias towards smaller particles. In addition, we took a sample with a shovel (November 2015), weighting around $10 \mathrm{~kg}$, and sieved it (after drying) in the laboratory of reinforced concrete of our department, in TEI Athens.

Furthermore, we examined the errors occurring from the radial distortion of the photograph, with the use of a specialized software named FAUCCAL (Fully Automatic Camera Calibration). The input to this software is photographs of a chessboard pattern, taken from different angles. The algorithm then proceeds to extract object corner points, discard blunders, sort the valid nodes in pattern rows and columns and finally calibrate the camera by bundle adjustment (Douskos et al., 2008). For our camera (a Nexus 5 camera), the results are summarized in the following table.

Table 1 - Outcome of the camera calibration software.

\begin{tabular}{|c|c|}
\hline A Posteriori Standard Error Sigma (pixels) & Sigma $=0.958$ \\
\hline Radial Distortion Parameters & $\mathrm{k} 1=1.282 \mathrm{e}-008 \pm 2.55 \mathrm{e}-010$ \\
$\mathrm{k} 2=-1.713 \mathrm{e}-015 \pm 1.42 \mathrm{e}-0162.5$ \\
\hline
\end{tabular}

By Table 1, we conclude that the error introduced by the radial distortion (sigma) is small, its order of magnitude being approximately one pixel that is $\sim 0.5 \mathrm{~mm}$.

The photographs were inserted into Autocad and scaled with the measuring tape. It is a fact, that for most cases, particles lie flat with the b-axis plane parallel to the photographic plane, so the shortest visible axis is the b-axis. After scaling of the photographs, the b-axes of the stones that fell onto the grid intersections were measured to the nearest $\mathrm{mm}$, leaving out the ones that fell under leaves or other obstacles. This procedure gave around 190 measurements, covering roughly $3.5 \mathrm{~m}^{2}$.

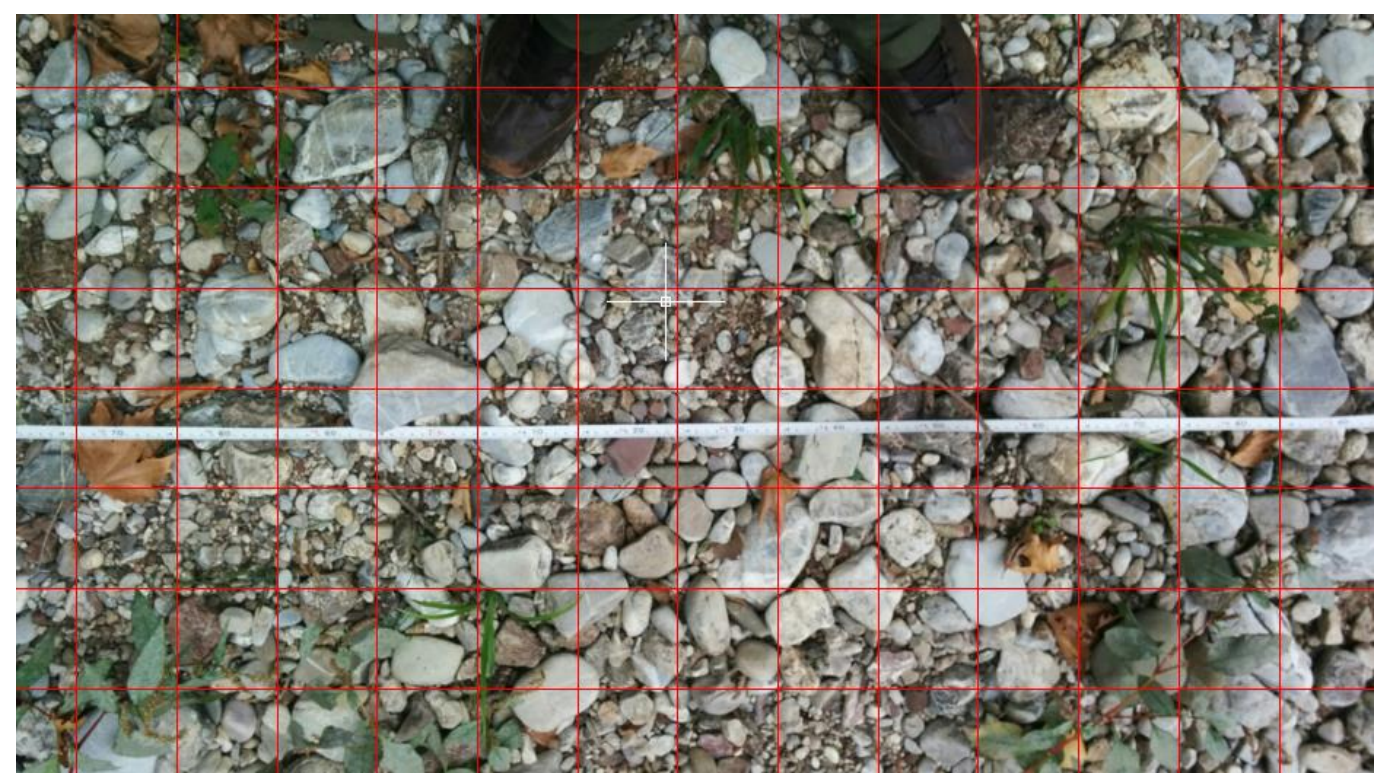

Figure 5 - One of the 3 photographs that were used for the grid count. Grid spacing is $10 \mathrm{~cm}$.

Before we proceed to the diagrams and figures of the results, we recapitulate, in the following table, the basic formulas for the calculation of the geometric distribution parameters. 
Table 2 - Statistical characteristics of the $\Psi$ size distribution.

(after Parker, 2004)

\begin{tabular}{|l|l|}
\hline$D_{i}=\sqrt{D_{b, i} D_{b, i+1}}, \quad \Psi_{i}=\frac{\Psi_{b, i}+\Psi_{b, i+1}}{2}$, & $\begin{array}{l}\mathrm{N}+1 \text { bounds defines N grain size ranges. The } \\
\text { ith grain size range is defined by }\left(\mathrm{D}_{\mathrm{b}, \mathrm{i}}, \mathrm{D}_{\mathrm{b}, \mathrm{i}+1}\right)\end{array}$ \\
$f_{i}=f_{f, i+1}-f_{f, i}$ & and $\left(\mathrm{f}_{\mathrm{f}, \mathrm{i}}, \mathrm{f}_{\mathrm{f}, \mathrm{i}+1}\right)$
\end{tabular}

\section{Results}

The cumulative distributions from the two methods gave the following results.

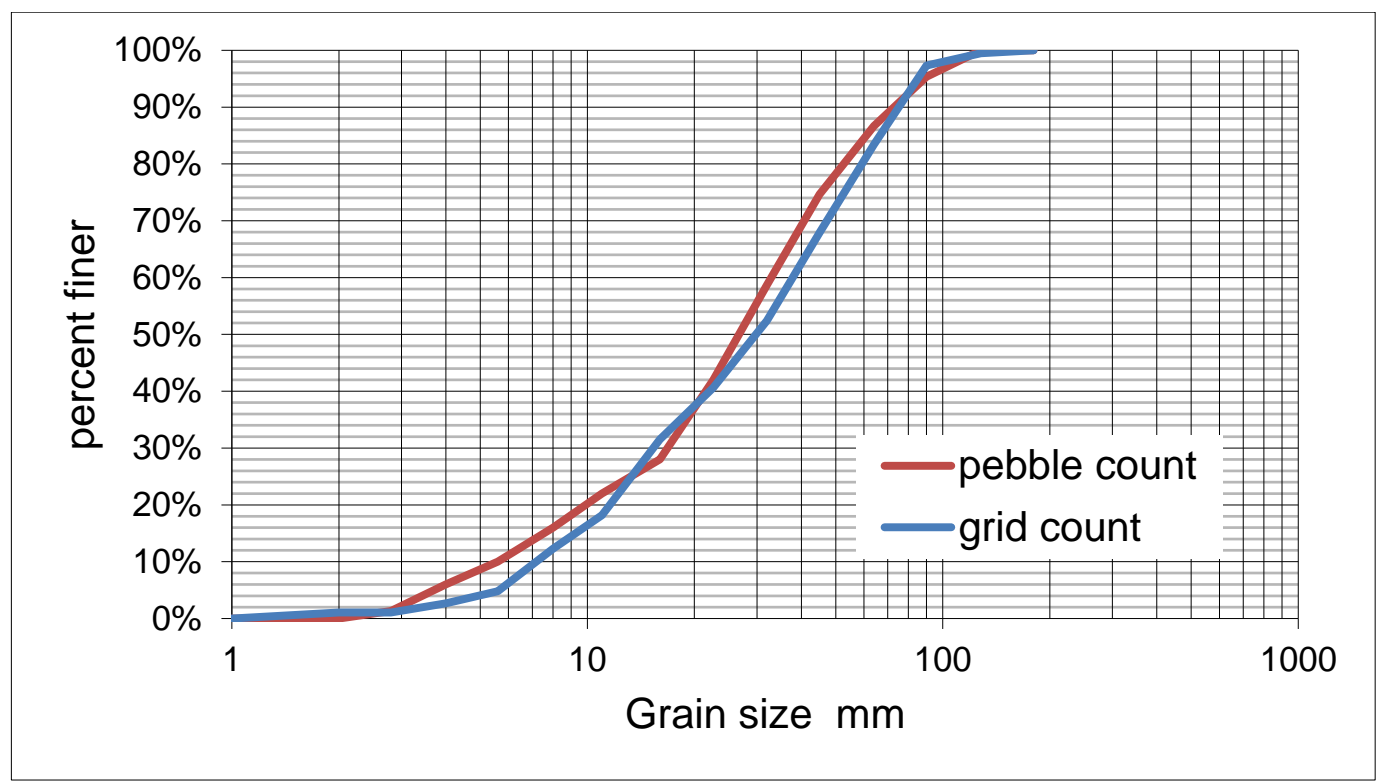

Figure 6 - The results of the measurements. It can be seen that grid count curve lies almost constantly to the right of the pebble count curve suggesting a more "coarse" distribution.

The results of the two distributions can be also given in a tabular form.

Figure 6 and Table 2 reveal that the cumulative grain size distribution that was calculated from the photographic grid count is coarser. This is mainly due, as we already mentioned, to the fact that ruler measurements of $b$-axes on photographs correspond to sieve results from round-hole sieves and need to be converted before they can be compared to standard sieve results from square-hole sieves. In order for this correction to be possible, the ratio of c/b axes must be known (and also, considered constant for all size classes). This correction is given by the following figure 7 . 
Table 3 - Significant numbers for the two GSD.

\begin{tabular}{|l|c|c|}
\hline \multicolumn{1}{|c|}{ all numbers in mm } & pebble count & grid count \\
\hline Geometric mean & 23.3 & 25.6 \\
\hline Geometric standard deviation & 2.5 & 2.5 \\
\hline $\begin{array}{l}\text { D50 (size such that 50 percent of the sediment } \\
\text { is finer) }\end{array}$ & 26.7 & 29.8 \\
\hline D16 & 8.0 & 9.8 \\
\hline D84 & 59.2 & 64.9 \\
\hline D25 & 13.3 & 13.3 \\
\hline D75 & 45.5 & 52.8 \\
\hline
\end{tabular}

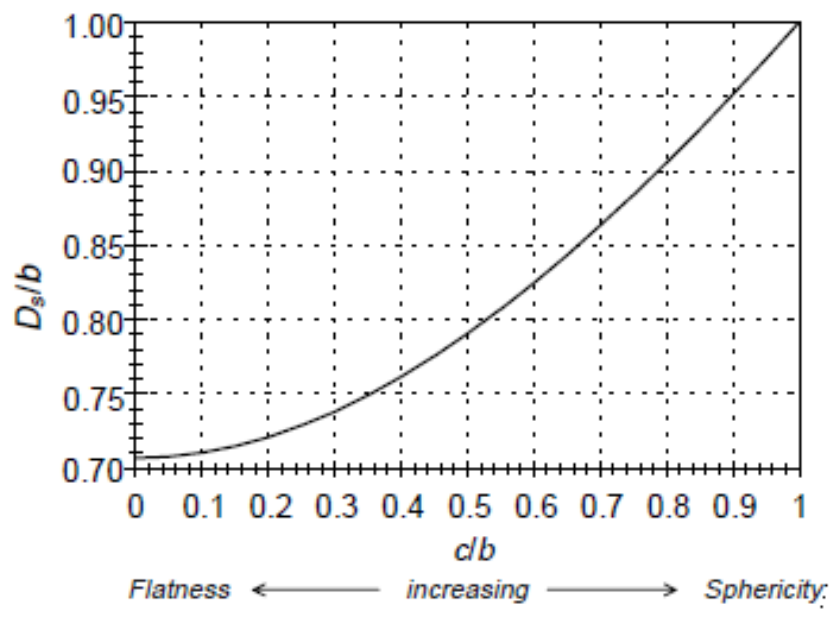

Figure 7 - Ratio of square-hole sieve opening $D_{s}$, to measured b-axis, as a function of particle flatness, i.e. the ratio of $\mathrm{c} / \mathrm{b}$. (Church et al., 1987).

In our case, this ratio was known due to a complete gravelometric survey at various reaches of the river (measurements of all 3 axes plus curvature angles of the particles) that had taken place in October 2014. The flatness of the sediment particles was found to vary between $0.55 \div 0.65$. Taking an average of 0.6 , Figure 7 gives us a $D_{s} / \mathrm{b}$ ratio equal to 0.83 . The whole series of grid size measurements was then multiplied with this conversion factor to derive the corrected grid count. Results are shown in the following figure and table.

\subsection{Discussion - Conclusions}

Photographic techniques for the purpose of acquiring grain size distributions of fluvial sediment are old, and some of their aspects have been debated for long. For instance, Kellerhals and Bray (1971), found that the mean particle size on photographic analyses was $5 \mathrm{~mm}$ smaller than that obtained by sieving. Adams (1979), found that this discrepancy becomes larger with increasing particle size. It is a fact that this technique is prone to bias against smaller particles. We could add, from our own experience, that smaller particles, when (usually) packed between larger ones, tend to expose their $c$-axes instead of the b-axes. The errors introduced by the radial distortion of the photograph are small, but they also constitute to make measurements of particles smaller than 5 or $6 \mathrm{~mm}$, prone to error. Another disadvantage of the photographic method, is that is very dependent on the operator (the one who measures on the screen), so it is mandatory that he/she must have a good prior 
experience in manual measuring (gravelometers and rulers). The use of a good camera is, of course, recommended.

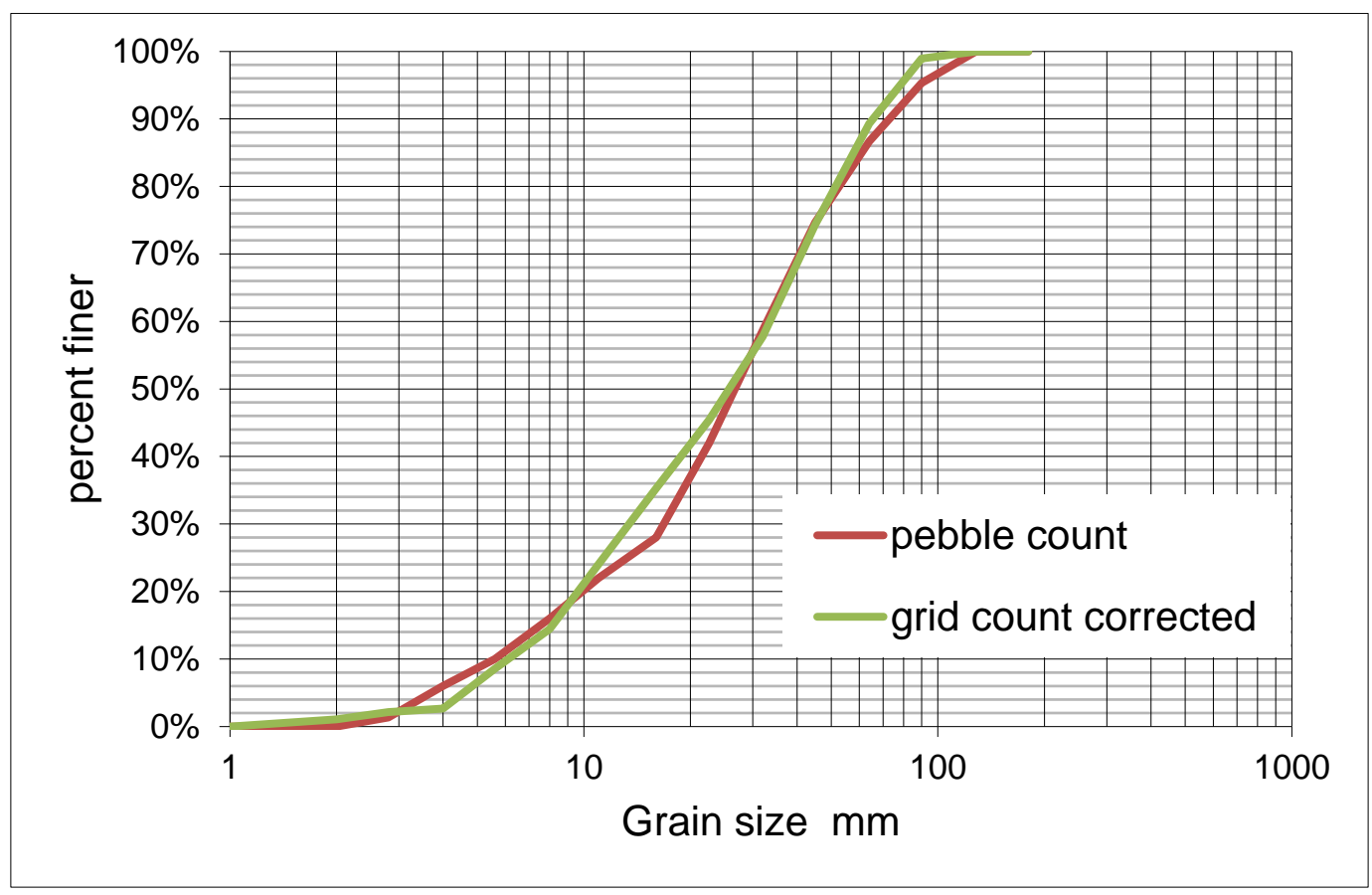

Figure 8 - The cumulative distribution of the grid count after its correction, fits the pebble count distribution much better.

Table 4 - Significant numbers for the two GSD after correction.

\begin{tabular}{|l|c|c|}
\hline \multicolumn{1}{|c|}{ all numbers in mm } & pebble count & $\begin{array}{c}\text { grid count } \\
\text { corrected }\end{array}$ \\
\hline Geometric mean & 23.3 & 22.1 \\
\hline Geometric standard deviation & 2.5 & 2.5 \\
\hline $\begin{array}{l}\text { D50 (size such that 50 percent of the sediment } \\
\text { is finer) }\end{array}$ & 26.7 & 25.7 \\
\hline D16 & 8.0 & 7.8 \\
\hline D84 & 59.2 & 59.2 \\
\hline D25 & 13.3 & 11.3 \\
\hline D75 & 45.5 & 45.7 \\
\hline
\end{tabular}

It can be seen that the corrected GSD is a much better fit of the pebble count derived GSD.

We can conclude that if the conditions are favourable (all particle b-axes are fully visible and parallel to the photographic plane), and the study is not very much concerned with fines, this method can save valuable field time, given that, for the site(s) studied, a general knowledge base exists already.

\section{References}

Adams, J., 1979. Gravel size analysis from photographs, Journal of the Hydraulics Division, ASC E, 105(HY10): 1247-1255. 
Bornovas, I. and Rondoyanni, Th., 1983. Geological Map of Greece, Scale 1:500,000, Institute of Geology and Mineral Exploration, Athens.

Bunte, K. and Abt, S., 2001. Sampling Surface and Subsurface Particle-Size Distributions in Wadable Gravel- and Cobble-Bed Streams for Analyses in Sediment Transport, Hydraulics, and Streambed Monitoring, Rocky Mountain Research Station, USDA, Forest Service, General Technical Report RMRS-GTR-74.

Church, M., McLean, D.G. and Walcott, J.F., 1987. River bed gravels: sampling and analysis. In: S ediment Transport in Gravel-Bed Rivers, Thorne, C.R., Bathurst, J.C. and Hey, R.D., eds., J ohn Wiley and Sons, Chichester, 43-88.

Douskos, V., Kalisperakis, I., Karras, G. and Petsa, E., 2008. Fully automatic camera calibration using regular planar patterns, International Archives of the Photogrammetry, Remote Sensing and Spatial Information Sciences, XXXVII/B5, 21-26.

Katsafados, P., Kalogirou, S., Papadopoulos, A. and Korres, G., 2012. Mapping Long-Term Atmos pheric Variables over Greece, Journal of Maps, 8, 181-184.

Kellerhals, R. and Bray, D.I., 1971. Sampling procedures for coarse fluvial sediments, Journal of $t$ he Hydraulics Division, ASCE, 97(HY8), 1165-1180.

Parker, G., 2004. 1D Sediment Transport Morphodynamics with applications to Rivers and turbidity currents, e-book.

Wentworth, C., 1922. A Scale of Grade and Class Terms for Clastic Sediments, The Journal of Geology, 30(5), 377-392. 